\title{
A EVOLUÇÃO DAS PRÁTICAS DE USO DA INTERNET PARA DIVULGAÇÃO DAS CONTAS PÚBLICAS NA UNIVERSIDADE FEDERAL DE SANTA CATARINA
}

\author{
ORION AUGUSTO PLATT NETO \\ FLÁVIO DA CRUZ \\ AUDÍ LUIZ VIEIRA
}

\begin{abstract}
Resumo
A divulgação das contas públicas constitui uma prática orientada para a transparência governamental, que é considerada um princípio da gestão fiscal responsável, associada ao princípio constitucional da publicidade. Tais princípios são plenamente aplicáveis às universidades públicas brasileiras. Neste sentido, o presente artigo tem o objetivo de apresentar a evolução das práticas adotadas pela Universidade Federal de Santa Catarina (UFSC) para divulgação de suas contas públicas por meio da Internet. Este artigo é baseado na repetição, no ano de 2009, de duas pesquisas realizadas anteriormente (nos anos de 2004 e de 2006), de modo a propiciar percepção da evolução ocorrida, com base na comparação entre três momentos de observação. Do ponto de vista da sua natureza, trata-se de uma pesquisa aplicada, para a qual foi adotada uma abordagem qualitativa. Foi realizada uma revisão de literatura para formação da base conceitual e legal para abordagem do problema. A pesquisa utilizou a observação direta das práticas adotadas pela UFSC para divulgação de suas contas públicas. A partir da identificação de funcionalidades e limitações das práticas das unidades da UFSC na divulgação das contas públicas, ao longo do tempo abrangido, foi possível apresentar sugestões para o aprimoramento da publicidade com o uso da Internet.
\end{abstract}

Palavras-chave: transparência governamental, universidades públicas, contas públicas. 


\section{INTRODUÇ̃̃̃O}

As universidades públicas brasileiras são entidades que compõem a administração pública. Comumente são constituídas sob as formas jurídicas de autarquias ou fundações, componentes da administração indireta, e são dependentes de recursos públicos. Em função disto, são obrigadas, conforme os artigos 37 e 70 da Constituição Federal, a prestar contas do uso de seus recursos e respeitar os princípios da publicidade e da transparência.

A transparência governamental, que representa um tema de relevante para a democracia, recebeu maior destaque em leis posteriores à Constituição Federal de 1988. O uso da Internet para divulgação das contas públicas, que constitui uma abordagem relativamente recente, ganhou destaque e obrigatoriedade a partir da Lei ${ }^{\circ}$ 9.755, em 1998, e da Lei de Responsabilidade Fiscal, em 2000.

Neste sentido, entende-se necessário acompanhar como tais demandas constitucionais e legais estão sendo cumpridas e como a modernização imposta está sendo oferecida pela administração pública, incluindo as universidades.

A LRF fundamenta-se em princípios como o planejamento, a transparência e a participação popular. A participação popular depende da transparência das ações governamentais e das contas públicas, pois sem dados e informações as decisões são prejudicadas. Destaca-se que a transparência é um conceito mais amplo do que a publicidade, isto por que uma informação pode ser pública mesmo não sendo relevante, confiável, tempestiva, útil e compreensível.

Mais do que garantir o atendimento das normas legais, as iniciativas de transparência nas universidades constituem uma política de gestão responsável que favorece o exercício da cidadania pela população. Potencialmente, a atitude poderá servir de estímulo aos estudantes, professores e demais servidores, contribuindo para o hábito de solicitar esclarecimentos junto às entidades governamentais.

Neste contexto, o presente artigo tem o objetivo de apresentar a evolução das práticas adotadas pela Universidade Federal de Santa Catarina (UFSC) para divulgação de suas contas públicas por meio da Internet. Os resultados apresentados no artigo são baseados na repetição, no ano de 2009, de duas pesquisas realizadas anteriormente, nos anos de 2004 e de 2006. Deste modo, busca-se oferecer aos leitores oportunidade para perceber a evolução ocorrida, com base na comparação entre três momentos de observação.

Deste modo, a pesquisa que embasou o artigo utilizou a observação direta das práticas adotadas pela Universidade Federal de Santa Catarina (UFSC) para publicidade de suas contas públicas, a partir da Internet. As classificações da pesquisa, bem como o detalhamento dos procedimentos metodológicos, encontram-se na seção 3, após a revisão de literatura que fundamenta o tema, constante na seção a seguir.

\section{REVISÃO DE LITERATURA}

\subsection{Publicidade e transparência das contas públicas}

A publicidade na administração pública brasileira está estabelecida como princípio no artigo 37 da Constituição Federal de 1988 e detalhada em seu $\S 1^{\circ}$, conforme transcrito a seguir:

Art. 37. A administração pública direta e indireta de qualquer dos Poderes da União, dos Estados, do Distrito Federal e dos Municípios obedecerá aos princípios de legalidade, impessoalidade, moralidade, publicidade e eficiência e, também, ao seguinte: $[\ldots]$

$\S 1^{\circ}$ - A publicidade dos atos, programas, obras, serviços e campanhas dos órgãos públicos deverá ter caráter educativo, informativo ou de orientação social, dela não 
podendo constar nomes, símbolos ou imagens que caracterizem promoção pessoal de autoridades ou servidores públicos.

Extrai-se do princípio da publicidade que o povo tem o direito de conhecer os atos praticados na administração pública, para o exercício do controle social, derivado do exercício do poder democrático. Destaca-se o "caráter educativo, informativo ou de orientação social" das divulgações, exigido pelo artigo 37 da $\mathrm{CF} / 88$ que revela a preocupação da assembléia constituinte com a compreensibilidade das informações para o controle social.

Além disso, o artigo $5^{\circ}$ da Constituição Federal assegura como fundamental o direito de receber informações dos órgãos públicos:

Art. $5^{\circ}$ Todos são iguais perante a lei, sem distinção de qualquer natureza, garantindo-se aos brasileiros e aos estrangeiros residentes no País a inviolabilidade do direito à vida, à liberdade, à igualdade, à segurança e à propriedade, nos termos seguintes: [...]

XXXIII - todos têm direito a receber dos órgãos públicos informações de seu interesse particular, ou de interesse coletivo ou geral, que serão prestadas no prazo da lei, sob pena de responsabilidade, ressalvadas aquelas cujo sigilo seja imprescindível à segurança da sociedade e do Estado;

Deste modo, exceto para informações justificadamente sigilosas, nos termos da Lei $\mathrm{n}^{\mathrm{o}}$ 11.111/2005, os órgãos públicos devem prestar informações aos cidadãos, sob pena de responsabilidade.

De maneira complementar, o ordenamento jurídico prevê várias normas que disciplinam a prestação de contas dos gestores públicos ao poder público e à comunidade em geral.

No ano de 2000, com a publicação da Lei Complementar $n^{0} 101$, conhecida como Lei de Responsabilidade Fiscal (LRF), a exigência de transparência recebeu um novo reforço no âmbito estatal brasileiro. Cruz et al (2001, p. 183) apresentam o entendimento dado à transparência na LRF da seguinte forma:

A transparência na gestão físcal é tratada na Lei como um princípio de gestão, que tem por finalidade, entre outros aspectos, franquear ao público acesso a informações relativas às atividades financeiras do Estado e deflagrar, de forma clara e previamente estabelecida, os procedimentos necessários à divulgação dessas informações.

A transparência, como um princípio da gestão fiscal responsável, pressupõe a publicidade, a relevância e a compreensibilidade das informações, não se restringindo meramente ao fato de uma informação ter sido publicada.

São considerados instrumentos de transparência da gestão fiscal, conforme a LRF (art. 48): os "planos, orçamentos e lei de diretrizes orçamentárias; as prestações de contas e o respectivo parecer prévio; o Relatório Resumido da Execução Orçamentária e o Relatório de Gestão Fiscal; e as versões simplificadas desses documentos".

\subsection{Divulgação das contas públicas a partir da Internet}

A Internet como meio para o fortalecimento das relações entre o governo e o cidadão, se desenvolveu significativamente no Brasil e no mundo a partir da década de 1990. No entanto, apenas uma parcela reduzida da população brasileira é usuária da Internet. Conforme dados PNAD (Pesquisa Nacional por Amostra de Domicílios), do IBGE (2009), em 2007, cerca de 15 milhões de domicílios tinham pelo menos um microcomputador, número este que representa $27 \%$ do total de domicílios no país, mais que os $22,4 \%$ de 2006 . Nas casas com computadores, 76\% tinham acesso à Internet, contra 66\% em 2001. Naquele ano, 6 milhões de residências tinham computador, sendo 4 milhões delas com acesso à Internet. 
A primeira iniciativa legal no sentido de incorporar a obrigatoriedade da divulgação de informações das contas públicas na Internet surgiu por meio da Lei $\mathrm{n}^{\circ}$ 9.755/1998, que criou a página da Internet (homepage) Contas Públicas ( $<$ www.contaspublicas.gov.br $>$ ). Por meio de tal página, todas as entidades gestoras de recursos públicos são obrigadas a disponibilizar determinadas informações orçamentárias e financeiras mensalmente.

Quanto à forma de divulgação das contas públicas, a LRF estabelece em seu artigo 48 que deve ser dada ampla divulgação aos instrumentos de transparência citados na subseção anterior, inclusive em meios eletrônicos de acesso público, como é o caso da Internet.

No ano de 2009, foi publicada a Lei Complementar $\mathrm{n}^{\circ} 131$, de 27 de maio, que alterou a LRF e trouxe novidades que afetaram diretamente a divulgação das contas públicas a partir do uso da Internet. Foram acrescentados novos dispositivos à LRF, dentre os quais se destaca a determinação de que sejam disponibilizadas, em tempo real, informações pormenorizadas sobre a execução orçamentária e financeira da União, dos estados, do Distrito Federal e dos municípios.

Deste modo, a partir do ano de 2009, com prazos entre um e quatro anos para cumprimento, todos os entes estão obrigados a disponibilizar, em tempo real, informações pormenorizadas sobre a execução orçamentária e financeira. Tal ação demandará a adoção de um sistema integrado de administração financeira e controle, que atenda a padrão mínimo de qualidade estabelecido pelo Poder Executivo da União (Secretaria do tesouro Nacional, do Ministério da Fazenda - STN/MF) e que permita a disponibilização das informações exigidas.

As informações que deverão estar disponíveis a qualquer pessoa física ou jurídica são referentes (art. 48-A da LRF):

a) Quanto à despesa: todos os atos praticados pelas unidades gestoras no decorrer da execução da despesa, no momento de sua realização, com a disponibilização mínima dos dados referentes ao número do correspondente processo, ao bem fornecido ou ao serviço prestado, à pessoa física ou jurídica beneficiária do pagamento e, quando for o caso, ao procedimento licitatório realizado.

b) Quanto à receita: o lançamento e o recebimento de toda a receita das unidades gestoras, inclusive referente a recursos extraordinários.

Qualquer cidadão, partido político, associação ou sindicato é parte legítima para denunciar ao respectivo Tribunal de Contas e ao órgão competente do Ministério Público o descumprimento das prescrições estabelecidas na LRF (art. 73-A da LRF), tais como as relativas à publicação de informações.

Destaca-se também a criação, no ano de 2004, do Portal da Transparência (<www.portaltransparencia.gov.br >), da Controladoria-Geral da União (CGU, 2009), que traz informações sobre a aplicação de recursos do governo federal, abrangendo transferências, convênios e aplicações diretas.

Ainda por parte de CGU, foi editada a Portaria $n^{\circ} 262$, de 2005, que estabelece que os órgãos e entidades do Poder Executivo Federal sujeitos a tomada e prestação de contas anuais manterão, em seus sítios eletrônicos na Internet, página com o título "Processos de Contas Anuais", na qual se dará a divulgação dos relatórios e dos certificados de auditoria, com pareceres do órgão de controle interno, e dos pronunciamentos dos Ministros de Estado supervisores das áreas ou das autoridades de nível hierárquico equivalente, contidos nos processos de contas anuais (CGU, 2005).

Nota-se que não há um impedimento ou proibição para que os entes estatais em geral, ou as Instituições Federais de Ensino em particular, sejam criativos e busquem, de forma constante, aproximar as modalidades de veiculação de dados às necessidades de simplificação manifestadas ou percebidas junto aos usuários. 


\subsection{As contas públicas das universidades e seus usuários}

O entendimento assumido nesta pesquisa para o termo "contas públicas" é: o conjunto de dados e informações de natureza econômico-financeira das entidades públicas, produzidas pelos órgãos de contabilidade, planejamento e orçamento. Tais informações podem associar dados monetários com não monetários, de natureza financeira, orçamentária e operacional, das atividades organizacionais.

Nos registros da homepage Contas Públicas, regulada pelo Tribunal de Contas da União (TCU, 2009), constam as universidade e faculdades financiadas com recursos federais. No entanto, a consulta aos links oferecidos revelou que nenhuma das instituições possui informações de contas públicas cadastradas.

O motivo para isto está embasado no Ofício $n^{0}$ 301/2000-MEC/SPO/GAB, da Subsecretaria de Planejamento e Orçamento, da Secretaria Executiva do Ministério da Educação, em 25 de maio de 2000. Referido ofício comunica que em reunião realizada com a Secretaria de Controle Externo do TCU, concluiu-se que não cabe a inserção dos dados e informações na homepage contas públicas pelos órgãos descentralizados, à exceção do FNDE.

No Portal da Transparência, da Controladoria Geral da União (CGU, 2009), observouse que constam todas as Instituições Federais de Ensino Superior (IFES) com dados sobre as aplicações de recursos associadas ao Ministério da Educação, com as possibilidades de obtenção das contas públicas mencionadas na seção anterior.

O quadro a seguir demonstra os principais usuários externos das informações das contas públicas das universidades e traz uma síntese dos interesses presumíveis dos mesmos. Alguns destes são também usuários internos, quando utilizam as informações para realização de seus trabalhos junto à instituição.

\begin{tabular}{|l|l|}
\hline \multicolumn{1}{|c|}{ Usuários } & \multicolumn{1}{c|}{ Síntese dos Interesses Presumíveis } \\
\hline Alunos & $\begin{array}{l}\text { Exercer a participação política e o controle social, auxiliando a escolha e a atuação de } \\
\text { reitores, diretores de centros, chefes de departamentos e outros representantes que } \\
\text { atendam aos seus anseios. }\end{array}$ \\
\hline Servidores & $\begin{array}{l}\text { Exercer a participação política e o controle social, auxiliando a escolha e a atuação de } \\
\text { reitores, diretores de centros, chefes de departamentos e outros representantes, que } \\
\text { atendam aos seus anseios. Seus interesses abrangem assuntos de classe relacionados a } \\
\text { condições de trabalhos, que dependam de recursos financeiros. }\end{array}$ \\
\hline Fornecedores & $\begin{array}{l}\text { Decisão de venda à instituição, através do conhecimento da demanda, da capacidade e da } \\
\text { execução de pagamentos. }\end{array}$ \\
\hline $\begin{array}{l}\text { Sindicatos dos } \\
\text { Servidores }\end{array}$ & $\begin{array}{l}\text { Negociar remunerações, condições gerais de trabalho e benefícios de servidores docentes } \\
\text { e técnico-administrativos. }\end{array}$ \\
\hline $\begin{array}{l}\text { ONGs: } \\
\text { Associações, etc. }\end{array}$ & Acompanhar e fiscalizar a ação governamental, de acordo com suas finalidades. \\
\hline Pesquisadores & Desenvolver estudos acadêmico-científicos sobre as universidades, sua gestão e finanças. \\
\hline $\begin{array}{l}\text { Meios de } \\
\text { Comunicação }\end{array}$ & Divulgação de notícias e matérias investigativas. \\
\hline
\end{tabular}

Quadro 1: Usuários externos das contas públicas e síntese de seus interesses Fonte: os autores.

Destaca-se que a lista não é exaustiva em termos de usuários ou de interesses. Existem ainda os usuários estatais, tais como o Tribunal de Contas da União (TCU), a ControladoriaGeral da União (CGU) e o Ministério Público Federal (MPF), que não foram incluídos na lista anterior em função de disporem de outros recursos computacionais para acesso e verificação das contas das instituições federais de ensino superior. 


\section{PROCEDIMENTOS METODOLÓGICOS}

Quanto a sua natureza, esta se trata de uma pesquisa aplicada. Quanto à forma de abordagem do problema, a pesquisa é classificada como qualitativa. Quanto aos objetivos, a pesquisa é exploratória. Foi realizada uma revisão de literatura para formação da base conceitual e legal para abordagem do problema.

A pesquisa que embasou o artigo utilizou a observação direta das práticas adotadas pela Universidade Federal de Santa Catarina (UFSC) para publicação de suas contas públicas, a partir da Internet, exclusivamente em sítios eletrônicos (páginas na Internet) da Instituição.

Os resultados apresentados no artigo são baseados na repetição, no ano de 2009 , de duas pesquisas realizadas anteriormente, nos anos de 2004 e de 2006, de modo a permitir a percepção da evolução ocorrida, com base na comparação entre três momentos de observação. Os períodos de observação que geraram as constatações foram: 11 a 18 de outubro de 2004; 11 a 18 de julho de 2006; e 7 a 9 de agosto de 2009.

Foram feitas visitas às páginas na Internet de diversas unidades da estrutura administrativa da UFSC, relacionadas à contabilidade, finanças, orçamento, auditoria, planejamento e informações institucionais. A partir das constatações sobre os dados e informações disponibilizados nos vários sítios eletrônicos institucionais visitados, foram indicadas as funcionalidades e limitações existentes. Com base no entendimento do que poderia favorecer uma correta divulgação das contas públicas da Universidade, foram apresentadas também algumas sugestões para aprimoramento, considerando as potencialidades informacionais, sem a pretensão de ser exaustivo na proposta.

Destaca-se que não foi feita uma distinção terminológica entre "dados" e "informações" nesta pesquisa, tendo em vista que a própria legislação aplicada e a linguagem popular predominante confundem os termos, sem haver prejuízos práticos significativos.

Por fim, é apresentada uma comparação dos dados coletados entre os momentos nos três anos de análise (2004, 2006 e 2009), com vistas a atingir o objetivo do artigo e, deste modo, apresentar a evolução das práticas adotadas pela Instituição para divulgação de suas contas públicas por meio da Internet.

\section{RESULTADOS DA PESQUISA}

\subsection{As práticas de divulgação das contas públicas da UFSC na Internet}

Nesta seção são apresentadas as práticas de divulgação das contas públicas da Universidade Federal de Santa Catarina (UFSC) realizadas a partir dos sítios eletrônicos (páginas na Internet) de unidades administrativas da Instituição. É feita a apresentação das unidades componentes da estrutura administrativa da UFSC, que divulgam informações sobre as contas públicas na Internet e uma descrição da natureza dos dados e informações disponibilizados.

Destaca-se ainda que é possível obter as contas públicas da UFSC no Portal da Transparência, da Controladoria-Geral da União (CGU), conforme tratado na fundamentação teórica. Todavia, o enfoque da pesquisa é diretamente sobre os sítios eletrônicos institucionais.

O período de observação que gerou as constatações a seguir foi de 7 a 9 de agosto de 2009, seguindo o detalhamento de procedimentos metodológicos descritos na seção 3 deste artigo. A seguir constam as funcionalidades disponibilizadas por cada uma das unidades administrativas selecionadas para observação. Na seção seguinte são comentadas algumas limitações e potencialidades identificadas com base nas constatações realizadas. 


\section{a) Departamento de Contabilidade e Finanças (DCF)}

O DCF está vinculado à Secretaria de Planejamento e Finanças (SEPLAN) e tem a missão de "tornar o processo financeiro/contábil mais ágil e eficiente, otimizando a integração do DCF com seus usuários". O Departamento é composto por uma coordenadoria e três divisões. Entre as competências da Divisão de Administração, estabelecida em seu regimento, estão: "Manter a Home Page do Departamento atualizada e em permanente sincronia com os seus usuários" e "Prestar informações a fornecedores, no que diz respeito aos pagamentos efetuados pela Instituição".

Em sua página na Internet ( $<$ http://www.reitoria.ufsc.br/dcf/>) são disponibilizadas algumas informações sobre as contas públicas. Quanto aos demonstrativos contábeis, estão publicados na Internet os quatro balanços da UFSC: orçamentário, financeiro, patrimonial e variações patrimoniais, referentes aos anos de 1999 a 2001. Deste modo, não estão disponíveis na rede os balanços referentes aos anos de 2002 a 2008, ou seja, dos exercícios financeiros seguintes já encerrados (até o termino das verificações desta pesquisa).

A página do DCF fornece também informações sobre pagamentos a fornecedores. Para os fornecedores, é possível cadastrar e-mail para receber notificações de pagamentos da UFSC. Qualquer pessoa pode consultar os pagamentos feitos às empresas com base no número do CNPJ da mesma, desde que o conheça.

\section{b) Departamento de Gestão Orçamentária (DGO)}

O DGO também é vinculado à SEPLAN e está encarregado do orçamento da UFSC, abrangendo a elaboração, proposta, acompanhamento e avaliação do orçamento, entre outras atividades relacionadas.

A página do DGO na Internet (<http://www.reitoria.ufsc.br/dgo/>) fornece as seguintes informações a respeito do orçamento da UFSC:

a) Demonstrativo do Orçamento de 2000 a 2009, com uma página em formato pdf, contendo os limites orçamentários executados conforme os principais grupos e subgrupos de despesas: pessoal e encargos sociais; outros benefícios sociais; outros custeios e capital - tesouro; e outros custeios e capital - diretamente arrecadados. No ano de 2008, a despesa totalizou R \$ 631,6 milhões, e para 2009 há uma previsão de R \$ 512,7 milhões;

b) Planilha do Orçamento Anterior, referente ao ano de 2008, conforme a Lei $n^{\circ} 11.647$, de 24/03/2008, com duas páginas em formato pdf. Esta planilha apresenta todos os programas de trabalho da UFSC, com suas respectivas especificações, naturezas e fontes de recursos das despesas. Para cada despesa especificada são apresentados os saldos e movimentações orçamentárias: saldo inicial, bloqueio, anulação, suplementação e total (saldo final), com total geral final de 667,6 milhões.

c) Proposta Orçamentária para o ano de 2009, conforme a Lei $\mathrm{n}^{\circ} 11.897$, de 30/12/2008, com duas páginas em pdf. Esta planilha apresenta todos os programas de trabalho da UFSC no corrente exercício, com suas respectivas especificações, naturezas e fontes de recursos das despesas. Para cada despesa é especificado o valor limite disponível no orçamento, com total geral de R \$ 512,7 milhões.

d) Execução Orçamentária Atual, referente a 2009, composta por seis tabelas em pdf, de uma página cada, abrangendo: Tesouro - Custeio e Capital; Tesouro - Pessoal; Convênios; Recursos Próprios - Fonte 250; Recursos Próprios - Fonte 280; e Recursos Próprios - Fonte 281. A penúltima e a antepenúltima tabelas citadas estavam inacessíveis na Internet, com a seguinte mensagem: "Erro 404 [...] "Objeto não encontrado! A URL requisitada não foi encontrada neste servidor. [...] $O$ link na página referida parece estar com algum erro ou desatualizado[...]". 
e) Relação de Empenhos Emitidos (ou Solicitados). Estão disponíveis apenas os referentes a janeiro a maio de 2009 , em pdf. O documento referente a maio contem 20 páginas. Estes relatórios contém, entre outros dados: número e data da solicitação de empenho; valor; fornecedor; unidade gestora do recurso (UGR, ou seja, o setor); e natureza da despesa.

f) Orçamento por unidade, referente ao exercício de 2009, com tabelas de despesas atualizadas até 30 de maio, referentes a: centros de ensino; colégios; pró-reitorias; entre outras unidades administrativas. O documento, intitulado "Quadro Demonstrativo do Orçamento da UFSC por Unidade Administrativa", está disponível em pdf e apresenta uma página cada, contendo: natureza da despesa, com código; valores orçados, liberados e saldos restantes para cada elemento de despesa.

\section{c) Departamento de Integração e Estatística (DIE)}

$\mathrm{O}$ DIE também é vinculado à SEPLAN. Anteriormente à atual estrutura administrativa, o setor era conhecido como Programa Integrado de Planejamento (PIP), sendo vinculado diretamente ao Gabinete do Reitor. O DIE possui, entre outras, as seguintes atribuições:

1. Construir modelos e simular cenários alternativos para subsidiar a formulação de políticas e diretrizes de gestão e de desenvolvimento institucional;

2. Promover atividades de elaboração de planos globais, planos diretores de gestão, programas e projetos de desenvolvimento da Universidade;

3. Desenvolver estudos de planejamento e elaborar normas e procedimentos aplicáveis nos processos de planejamento institucional e controle da execução de planos, programas e projetos;

A página do DIE na Internet (<http://www.die.ufsc.br/>) contém, no que tange às contas públicas: o Relatório de Gestão da UFSC, referente aos anos de 2000 a 2008; e o Boletim de Dados da UFSC, referente aos anos de 2000 a 2007.

Constam ainda na página do PIP: o Plano de Desenvolvimento Institucional (2004); o Plano Institucional (2004); e o relatório UFSC em Números (2000 a 2008). Constam ainda links para os documentos relativos ao orçamento (atual, anterior e de acompanhamento da execução) constantes na página do DGO/SEPLAN/UFSC.

Nos Relatórios de Gestão da UFSC referentes aos anos de 2004 a 2008, encontram-se informações exigidas pelo Tribunal de Contas da União por meio da Decisão $n^{\circ}$ 408/2002 e Decisão Normativa TCU $n^{\circ} 62$. Tal seção do relatório abrange indicadores, como o de custo por aluno, e a avaliação do cumprimento dos objetivos e metas constante no Plano Plurianual.

\section{d) Auditoria Interna (AUDIN)}

A unidade de Auditoria Interna (AUDIN) da UFSC tem as seguintes finalidades básicas: "fortalecer a gestão; racionalizar as ações de controle e prestar apoio aos órgãos do Sistema de Controle Interno do Poder Executivo Federal". Entre suas atividades está: "Examinar e emitir parecer sobre a prestação de contas anual da Universidade e tomadas de contas especiais" (AUDIN, 2009).

Na página da AUDIN na Internet (<http://www.audin.ufsc.br>) são divulgados:

a) Os Relatórios de Atividades anuais de 1998 a 2008, em pdf. Nestes, a AUDIN divulga as ressalvas apontadas com as devidas recomendações constantes dos Relatórios de Auditoria da Controladoria-Geral da União (CGU) e as determinações do Tribunal de Contas da União (TCU). Associadas às ressalvas, recomendações e determinações, são também divulgadas as ações adotadas pelas diversas unidades administrativas para o saneamento das impropriedades indicadas, além de registrar as pendências ainda existentes. 
b) Os Pareceres Anuais da AUDIN sobre os processos de prestações de contas da UFSC, entre os anos de 2002 a 2008, em pdf. Tais pareceres abrangem análises e considerações sobre: os balanços públicos da UFSC; as metas previstas no PPA (Plano Plurianual) e na LDO (Lei de Diretrizes Orçamentárias); os indicadores de desempenho utilizados; a regularidade dos processos licitatórios; o gerenciamento da execução dos convênios, acordos e ajustes; o cumprimento de suas recomendações no âmbito da unidade; o cumprimento das decisões e recomendações dos conselhos fiscais, dos conselhos de administração e outros órgãos de fiscalização da atividade, quando for o caso; entre outros aspectos.

c) O Plano de Atividades da Auditoria Interna (PAINT) para o ano de 2009. Este Plano contém: uma descrição das atividades de auditoria interna (áreas, objetivos, escopo, locais, forma, tipo, duração, etc.); e o cronograma de atividades planejadas, conforme a carga-horária dos profissionais, entre outros detalhes programáticos.

Constam ainda na página da AUDIN: manuais de orientação e informes.

\subsection{Identificação de limitações e potencialidades para aprimoramento}

A seguir estão identificadas algumas das limitações identificadas nas práticas adotadas pela UFSC para divulgação de suas contas públicas na Internet. São abordados os dados e informações oferecidas pela UFSC por meio de seus órgãos específicos de contabilidade, orçamento, planejamento e auditoria, apresentados na subseção anterior. A partir das constatações, são apresentadas algumas sugestões para aprimoramento, considerando as potencialidades de uso da Internet como recurso para a promoção da transparência.

a) $\mathrm{Na}$ página do Departamento de Contabilidade e Finanças (DCF) não estavam disponíveis os balanços públicos referentes aos sete últimos exercícios financeiros encerrados (2002 a 2008), o que torna a informação pouco útil para os usuários. Poderiam ser fornecidos dados conjuntos de diversos anos num único demonstrativo, no sentido de facilitar a captura e tabulação de dados em séries históricas.

b) Os cabeçalhos nos balanços disponibilizados na página do DCF estão incompletos. Poderiam ser seguidos os padrões de cabeçalhos utilizados pelo Departamento de Gestão Orçamentária (DGO).

c) Como é comum na administração pública de modo geral, não constam notas explicativas aos balanços públicos da UFSC. As notas explicativas constituem parte integrante dos demonstrativos contábeis, sendo essenciais para a compreensão de diversas contas e da situação patrimonial.

d) O formato que o DCF utilizou para fornecer os balanços (html) facilita a visualização no navegador de Internet, mas dificulta a impressão e a transposição dos demonstrativos para editores de textos e planilhas eletrônicas. Em função disto, poderia ser fornecida uma versão alternativa dos balanços na forma de planilha eletrônica (Excel, por exemplo), no sentido de facilitar a captura de dados pelos interessados e também no formato adobe acrobat (pdf) para garantir uma impressão que não desconfigure em relação ao formato original.

e) $\mathrm{O}$ recurso oferecido pelo $\mathrm{DCF}$, de permitir a consulta dos pagamentos aos fornecedores da UFSC via Internet, garante uma publicidade detalhada dos desembolsos. Sugere-se apenas que o mecanismo de busca permita uma listagem completa ou a consulta mediante o nome ou parte do nome dos fornecedores, tendo em vista que nem todos os usuários possuem conhecimento dos CNPJs dos fornecedores da UFSC.

f) Poderia ser dada publicidade via Internet o que é exigido no art. 16 da Lei $\mathrm{n}^{\circ}$ 8.666/1993, apresentando a relação mensal das compras, de maneira a "clarificar a identificação do bem comprado, seu preço unitário, a quantidade adquirida, o nome do 
vendedor e o valor total da operação, podendo ser aglutinadas por itens as compras feitas com dispensa e inexigibilidade de licitação". A relação mensal de empenhos emitidos, disponibilizada na página do DGO, minimiza a ausência da relação mensal de compras, embora não a substitua.

g) Ainda não foi disponibilizado pelo Departamento de Integração e Estatística (DIE) o Boletim de Dados da UFSC referente ao ano de 2008, sendo que já se passou mais da metade do ano de 2009.

h) O Boletim de Dados da UFSC deixou de fornecer os quatro balanços públicos, conforme era feito nos referentes aos anos de 2000 e 2001. A prática poderia voltar a ser realizada, especialmente em função de os dados na página do DCF também estarem desatualizados.

i) Os demonstrativos da execução orçamentária divulgados pelo DGO estão no formato pdf, o que facilita a visualização e a impressão, mas dificulta a transposição dos demonstrativos para planilha eletrônica. Poderia ser fornecida uma versão alternativa dos demonstrativos na forma de planilha eletrônica (Excel, por exemplo), no sentido de facilitar a captura de dados pelos interessados.

j) O Demonstrativo do Orçamento, de 2000 a 2009, constante na página do DGO, não apresentou qualquer atualização monetária por índice de preços. Este fato gera distorção na comparação de valores entre os anos, tendo em vista a inflação significativa ocorrida no período, dependendo do índice. Sugere-se adotar o IGP-DI (Índice Geral de Preços - Disponibilidade Interna), da Fundação Getúlio Vargas (FGV, 2009), por ser usualmente uma referência para contas públicas no Estado de Santa Catarina e ser um dos preferidos pelo Ministério da Educação em seus estudos.

k) Os demonstrativos sobre o orçamento, disponíveis na página do DGO, estão carentes de textos com explicações complementares. Todavia, em documentos paralelos, $\mathrm{O}$ DGO passou a fornecer ementários de elementos e subelementos de despesas, que favorecem a compreensão da terminologia da despesa orçamentária.

1) Embora a UFSC esteja dispensada de publicar suas contas na homepage Contas Públicas, do TCU, poderia ser ativado o link da referida página com as do DCF e do DGO. Este serviço atenderia usuários que se deparam com a homepage Contas Públicas em busca de informações sobre as contas da UFSC. Esta seria uma iniciativa pioneira, tendo em vista que nenhuma outra universidade pública utiliza a Homepage Contas Públicas.

m) O Relatório de Gestão divulga, entre outras informações, o custo do aluno, conforme metodologia do Tribunal de Contas da União. Segundo o Relatório de Gestão de 2008, o custo médio por aluno (equivalente, com Hospital Universitário) de R\$ 11.807,73 (UFSC, 2009).

n) Em todos os demonstrativos e seções de relatórios observadas, constatou-se o uso exclusivo de linguagem técnica, ou seja, sem alguma simplificação para leigos. Em alguns casos, constatou-se o uso de letras de tamanho reduzido, pouca atenção estética e ausência de legendas e de textos explicativos (fatores que tendem a inibir a consulta).

o) Exceto por dois casos, na página do DGO, todos os links verificados estavam com funcionamento adequado, ou seja, abriam as páginas e permitem acesso aos dados e informações que se esperava.

Destaca-se, por fim, que não houve a pretensão de esgotar as possibilidades de análise com os comentários e sugestões colocadas. Procurou-se apenas fazer colocações que levem a discussão sobre limitações e potencialidades para o uso da Internet numa perspectiva consistente de fornecimento de informações sobre as contas públicas aos usuários interessados. 


\subsection{Evolução das práticas de divulgação entre os anos}

No Quadro 2 encontra-se uma síntese comparativa entre as práticas de divulgação das contas públicas da UFSC na Internet entre momentos nos anos de 2004, 2006 e 2009.

\begin{tabular}{|c|c|c|c|}
\hline \multirow{2}{*}{$\begin{array}{c}\text { Aspectos Observados } \\
\text { em Páginas da } \\
\text { Internet de Setores } \\
\text { da UFSC } \\
\end{array}$} & \multicolumn{3}{|c|}{ Momentos de Observação } \\
\hline & $\begin{array}{l}11 \text { a } 18 \text { Outubro } \\
\text { de } 2004\end{array}$ & $\begin{array}{l}11 \text { a } 18 \text { de Julho } \\
\text { de } 2006\end{array}$ & $\begin{array}{c}07 \text { a } 09 \text { de Agosto } \\
\text { de } 2009\end{array}$ \\
\hline $\begin{array}{l}\text { a) Disponibilização } \\
\text { dos balanços públicos } \\
\text { (no DCF) }\end{array}$ & $\begin{array}{l}\text { Apenas referentes aos anos de } \\
1999 \text { a } 2001 .\end{array}$ & Persiste a situação. & Persiste a situação. \\
\hline $\begin{array}{l}\text { b) Cabeçalhos e notas } \\
\text { explicativas dos } \\
\text { balanços (no DCF) }\end{array}$ & $\begin{array}{c}\text { Cabeçalhos incompletos. } \\
\text { Ausência de Notas Explicativas } \\
\text { e outras informações } \\
\text { complementares. }\end{array}$ & Persiste a situação. & Persiste a situação. \\
\hline $\begin{array}{l}\text { c) Formatos de } \\
\text { disponibilização dos } \\
\text { balanços (no DCF) }\end{array}$ & $\begin{array}{l}\text { Apenas em html, o que dificulta } \\
\text { a impressão e a transposição } \\
\text { dos dados para outros } \\
\text { documentos. }\end{array}$ & Persiste a situação. & Persiste a situação. \\
\hline $\begin{array}{l}\text { d) Consulta de } \\
\text { pagamentos a } \\
\text { fornecedores (no DCF) }\end{array}$ & $\begin{array}{l}\text { Apenas mediante fornecimento } \\
\text { do CNPJ do fornecedor. }\end{array}$ & Persiste a situação. & Persiste a situação. \\
\hline $\begin{array}{l}\text { e) Disponibilização do } \\
\text { Boletim de Dados (no } \\
\text { PIP ou DIE) }\end{array}$ & $\begin{array}{l}\text { Disponibilização atualizada } \\
\text { (2000 a 2004) }\end{array}$ & $\begin{array}{l}\text { Ainda não divulgado o } \\
\text { referente a } 2005 . \\
(2000 \text { a 2004) }\end{array}$ & $\begin{array}{l}\text { Ainda não divulgado o } \\
\text { referente a 2008. } \\
(2000 \text { a 2007) }\end{array}$ \\
\hline $\begin{array}{l}\text { f) Apresentação dos } \\
\text { demonstrativos } \\
\text { orçamentários (no } \\
\text { DGO) }\end{array}$ & $\begin{array}{l}\text { Em formato de imagem, que } \\
\text { prejudica a impressão e a coleta } \\
\text { dos dados. }\end{array}$ & $\begin{array}{l}\text { Em formato html, que já é } \\
\text { uma alternativa melhor do } \\
\text { que em imagem, embora não } \\
\text { seja a ideal. }\end{array}$ & $\begin{array}{c}\text { Em formato pdf, que } \\
\text { oferece boa visualização e } \\
\text { praticidade, embora } \\
\text { dificulte a coleta de dados. }\end{array}$ \\
\hline $\begin{array}{l}\text { h) Fornecimento de } \\
\text { dados atualizados } \\
\text { monetariamente (no } \\
\text { DCF e no DGO) }\end{array}$ & $\begin{array}{c}\text { Apenas no DGO foram } \\
\text { fornecidos dados com } \\
\text { atualização por diversos índices } \\
\text { de preços, o que minimizava } \\
\text { distorções comparativas. }\end{array}$ & $\begin{array}{l}\text { Foram eliminados os ajustes } \\
\text { monetários. }\end{array}$ & Persiste a situação. \\
\hline $\begin{array}{l}\text { i) Informações } \\
\text { complementares às } \\
\text { tabelas orçamentárias } \\
\text { (no DGO) }\end{array}$ & Não constavam. & $\begin{array}{c}\text { Persiste a situação. Constam } \\
\text { algumas observações apenas } \\
\text { no Demonstrativo de } \\
\text { Orçamento de } 1995 \text { a } 2006 .\end{array}$ & $\begin{array}{l}\text { Persiste a situação. } \\
\text { Não consta nenhuma } \\
\text { informação. }\end{array}$ \\
\hline $\begin{array}{l}\text { j) Informação do custo } \\
\text { por aluno (em todos) }\end{array}$ & $\begin{array}{l}\text { A divulgação era feita pelo } \\
\text { extinto DPA. Os dados estavam } \\
\text { desatualizados e não havia } \\
\text { evidenciação metodológica. }\end{array}$ & $\begin{array}{c}\text { Segue metodologia do TCU, } \\
\text { sendo divulgada no Relatório } \\
\text { de Gestão. }\end{array}$ & $\begin{array}{l}\text { Mantém da divulgação no } \\
\text { Relatório de Gestão. }\end{array}$ \\
\hline $\begin{array}{l}\text { k) Relatórios da } \\
\text { Auditoria Interna (na } \\
\text { AUDIN) }\end{array}$ & $\begin{array}{l}\text { Apresentam as constatações de } \\
\text { auditorias e fiscalizações da } \\
\text { CGU e do TCU; e providências } \\
\text { tomadas pela Administração da } \\
\text { UFSC. }\end{array}$ & $\begin{array}{l}\text { Continua sendo dada a mesma } \\
\text { evidenciação. }\end{array}$ & $\begin{array}{c}\text { Foi ampliada a divulgação, } \\
\text { incluindo os pareceres } \\
\text { sobre as prestações de } \\
\text { contas e os planos de } \\
\text { atividades. } \\
\end{array}$ \\
\hline $\begin{array}{l}\text { 1) Atenção aos usuários } \\
\text { das informações (DCF } \\
\text { e DGO) }\end{array}$ & $\begin{array}{c}\text { Desatenção estética e } \\
\text { terminológica. Não constavam } \\
\text { explicações ou esclarecimentos } \\
\text { por escrito aos quadros e tabelas } \\
\text { fornecidos. } \\
\end{array}$ & $\begin{array}{l}\text { Persiste a situação. O DGO } \\
\text { fornece explicações sobre } \\
\text { como é elaborado e } \\
\text { distribuído o orçamento. }\end{array}$ & $\begin{array}{l}\text { O DGO passou a fornecer } \\
\text { ementários de elementos e } \\
\text { subelementos de despesas. } \\
\text { A estética está melhorando. }\end{array}$ \\
\hline $\begin{array}{l}\text { m) Funcionamento das } \\
\text { páginas (em todos) }\end{array}$ & $\begin{array}{c}\text { Diversos links quebrados (não } \\
\text { abriam as páginas e } \\
\text { informações pretendidas) } \\
\end{array}$ & Todos os links funcionando. & $\begin{array}{l}\text { Apenas dois links (no } \\
\text { DGO) não estavam } \\
\text { funcionando. }\end{array}$ \\
\hline \multicolumn{4}{|c|}{ Lista de Siglas constantes no Quadro: } \\
\hline \multicolumn{2}{|c|}{$\begin{array}{l}\text { DCF - Departamento de Contabilidade e Finanças } \\
\text { PIP - Programa Integrado de Planejamento } \\
\text { DIE - Departamento de Integração e Estatística } \\
\text { DGO - Departamento de Gestão Orçamentária }\end{array}$} & \multicolumn{2}{|c|}{$\begin{array}{l}\text { DPA - Dep. de Planejamento e Acompanhamento } \\
\text { CGU - Controladoria Geral da União } \\
\text { TCU - Tribunal de Contas da União }\end{array}$} \\
\hline
\end{tabular}

Quadro 2: Comparativo das situações observadas nos dois momentos

Fonte: dados da observação atual e adaptados das pesquisas anteriores. 
Com base na comparação realizada dos doze aspectos constantes no Quadro 2, observa-se que:

1) Cinco dos problemas ou situações identificados permanecem inalterados desde o primeiro momento de observação (itens "a", "b", "cc", “d" e "i").

2) Persiste ainda em 2009 o problema de desatualização do ano mais recente do Boletim de Dados, que foi observado inicialmente no segundo momento (no ano de 2006).

3) Manteve-se a ausência de atualização monetária de séries históricas orçamentárias disponibilizadas pelo DGO, que era feita até o ano de 2004.

4) Melhorou gradualmente a forma de disponibilização de documentos pelo DGO.

5) A informação de custo do aluno passou a ser divulgada de modo consistente nos Relatórios de Gestão, a partir do $2^{\circ}$ momento da observação (ano de 2006).

6) A AUDIN ampliou a divulgação de informações sobre as contas da Universidade e as auditorias e situações encontradas.

7) O DGO passou a fornecer ementários de contas, que podem auxiliar os usuários a entenderem seus relatórios, e a estética de apresentação dos demonstrativos melhorou em relação aos períodos anteriores.

8) Após terem sido corrigidos todos os problemas de links quebrados (arquivos inacessíveis), no ano de 2006, dois problemas foram encontrados na observação feita no ano de 2009.

Maiores detalhes sobre os aspectos pontuados e sintetizados no quadro, no que se refere ao período de observação referente ao ano de 2009, encontram-se nas subseções anteriores.

\section{CONSIDERAÇÕES FINAIS}

Considera-se atingido o objetivo deste artigo, tendo em vista que foi apresentada a evolução das práticas adotadas pela Universidade Federal de Santa Catarina (UFSC) para divulgação de suas contas públicas por meio da Internet.

$\mathrm{O}$ artigo, em sua revisão de literatura, apresentou considerações sobre o uso da Internet para divulgação das contas públicas por parte das universidades brasileiras. A base legal e conceitual revisada evidenciou a necessidade e a obrigatoriedade de as instituições públicas de ensino divulgarem suas contas na Internet. A transparência é considerada um princípio da gestão fiscal responsável, ligado ao princípio constitucional da publicidade.

A partir da identificação de limitações e de funcionalidades nas práticas adotadas pelos setores da UFSC na divulgação das contas públicas, foi possível apresentar sugestões para o aprimoramento da publicidade com o uso da Internet. Não houve a pretensão de esgotar as possibilidades de análise com os comentários e sugestões colocados. Procurou-se apenas fazer colocações que levem à discussão sobre limitações e possibilidades para o uso da Internet numa perspectiva consistente de fornecimento de dados sobre as contas públicas no caso específico da UFSC, visando contribuir para a prática do controle social esclarecido.

Com base em dados de pesquisas anteriores, realizadas sobre o mesmo tema, foi possível proceder a uma comparação das práticas utilizadas pela UFSC para a publicidade de suas contas públicas a partir do uso da Internet. A comparação de três momentos (nos anos de 2004, 2006 e 2009) permitiu perceber que houve algumas melhorias no uso da Internet para divulgação eletrônica das contas públicas. Por outro lado, alguns aspectos se mantiveram inadequados enquanto outros regrediram ao longo do tempo abrangido, o que destaca a necessidade de atenção ao tema por parte das autoridades administrativas. 
Para pesquisas futuras, sugere-se uma análise da qualidade das informações das contas públicas em termos de atendimento aos interesses dos usuários. Neste sentido, torna-se necessário realizar pesquisas junto aos usuários das informações.

Destaca-se, por fim, que para uma adequada transparência governamental, necessita-se de mais do que a divulgação das informações. A compreensibilidade dos dados e informações pelos usuários é condição indispensável. Neste sentido, faz-se necessário buscar formas alternativas para simplificar a linguagem, sensibilizar e motivar a comunidade universitária a consultar as contas de sua instituição, além de assegurar meios para aprendizado dos temas envolvidos.

\section{REFERÊNCIAS}

BRASIL. Constituição (1988). Constituição da República Federativa do Brasil: promulgada em 5 de outubro de 1988.Disponível em: <http://www.planalto.gov.br/ccivil_03/Constituicao/ Constituiçao.htm>. Acesso em: 16 jul. 2009.

Lei $\mathbf{n}^{\mathbf{0}}$ 4.320, de 17 de março de 1964. Estatui normas gerais de direito financeiro para elaboração e controle dos orçamentos e balanços da União, dos estados, dos municípios e do Distrito Federal. Disponível em: <http://www.planalto.gov.br/CCIVIL/Leis/L4320.htm>. Acesso em: 16 jul. 2009.

. Lei no 8.666, de 21 de junho de 1993. Regulamenta o art. 37, inciso XXI, da Constituição Federal, institui normas para licitações e contratos da Administração Pública e dá outras providências. Disponível em: $<$ http://www.planalto.gov.br/ccivil/Leis/L8666cons.htm>. Acesso em: 16 jul. 2009.

Lei $\mathbf{n}^{\circ} \mathbf{9 . 7 5 5}$, de 16 de dezembro de 1998. Dispõe sobre a criação de "homepage" na "Internet", pelo Tribunal de Contas da União, para divulgação dos dados e informações que especifica, e dá outras providências. Disponível em: <http://www.planalto.gov.br/ccivil/leis/L9755.htm>. Acesso em: 16 jul. 2009.

Lei $\mathbf{n}^{\mathbf{0}}$ 11.111, de 5 de maio de 2005. Regulamenta a parte final do disposto no inciso XXXIII do caput do art. 5o da Constituição Federal e dá outras providências. Disponível em: $<$ http://www.planalto.gov.br/ccivil_03/_Ato2004-2006/2005/Lei/L11111.htm>. Acesso em: 08 ago. 2009.

Lei Complementar $\mathbf{n}^{\mathbf{0}}$ 101, de 4 de maio de 2001 (Lei de Responsabilidade Fiscal). Estabelece normas de finanças públicas voltadas para a responsabilidade na gestão fiscal e dá outras providências. Disponível em: $<$ http://www.planalto.gov.br/CCIVIL/Leis/LCP/ Lcp101.htm>. Acesso em: 16 jul. 2009.

. Lei Complementar $\mathbf{n}^{0}$ 131, de 27 de maio de 2009. Acrescenta dispositivos à Lei Complementar no 101, de 4 de maio de 2000, que estabelece normas de finanças públicas voltadas para a responsabilidade na gestão fiscal e dá outras providências, a fim de determinar a disponibilização, em tempo real, de informações pormenorizadas sobre a execução orçamentária e financeira da União, dos Estados, do Distrito Federal e dos Municípios. Disponível em: $<$ http://www.planalto.gov.br/CCIVIL/Leis/LCP/Lcp131.htm>. Acesso em 6 junho 2009.

CGU - Controladoria-Geral da União. Presidência da República. Portal da Transparência. Disponível em: <http://www.portaltransparencia.gov.br>. Acesso em: 08 ago. 2009.

CGU - Controladoria-Geral da União. Presidência da República. Portaria no $\mathbf{n}^{\mathbf{2} 62}$, de 30 de agosto de 2005. A forma de divulgação dos relatórios e dos certificados de auditoria, com 
pareceres do órgão de controle interno, e dos pronunciamentos dos Ministros de Estado supervisores das áreas ou das autoridades de nível hierárquico equivalente, contidos nos processos de contas anuais, submete-se ao disposto nesta Portaria. Disponível em: $<$ http://www.cgu.gov.br/Legislacao/Arquivos/Portarias/p262_20050109b.pdf $>$. Acesso em: 08 ago. 2009.

CRUZ, Flávio da et al. Lei de responsabilidade fiscal comentada: Lei Complementar $\mathrm{n}^{\mathrm{o}} 101$, de 4 de maio de 2000. 2. ed. São Paulo: Atlas, 2001. 346 p.

FGV - Fundação Getulio Vargas. Divisão de Gestão de Dados do Instituto Brasileiro de Economia. Índices de preços. Disponível em: $<$ http://www2.fgv.br/dgd/asp/dsp_IGP.asp $>$. Acesso em: 20 jul. 2009.

IBGE - Instituto Brasileiro de Geografia e Estatística. PNAD - Pesquisa Nacional por Amostra de Domicílios 2007. Disponível em: <http://www.ibge.gov.br/home/estatistica/ populacao/trabalhoerendimento/pnad2007/default.shtm>. Acesso em 08 ago. 2009.

TCU - Tribunal de Contas da União. Homepage Contas Públicas. Disponível em: $<$ http://www.contaspublicas.gov.br>. Acesso em: 08 ago. 2009.

UFSC - Universidade Federal de Santa Catarina. AUDIN - Unidade de Auditoria Interna. Relatórios de Atividades. Homepage. Disponível em: <http://www.audin.ufsc.br/>. Acesso em: 08 ago. 2009.

DCF - Departamento de Contabilidade e Finanças. Secretaria de Planejamento e Finanças - SEPLAN. Balanços Públicos da UFSC. Homepage. Disponível em: $<$ http://www.reitoria.ufsc.br/dcf>. Acesso em: 08 ago. 2009.

DGO - Departamento de Gestão Orçamentária. Secretaria de Planejamento e Finanças - SEPLAN. Orçamentos da UFSC. Homepage. Disponível em: $<$ http://www.reitoria.ufsc.br/dgo >. Acesso em: 08 ago. 2009.

DIE - Departamento de Integração e Estatística. Secretaria de Planejamento e Finanças - SEPLAN. Homepage. Disponível em: <http://www.die.ufsc.br/>. Acesso em: 08 ago. 2009.

Relatório de Gestão 2008. Disponível em: $<$ http://www.die.ufsc.br/arquivos/ RELATORIO_GESTAO_2008.pdf>. Acesso em: 09 ago. 2009. 